Revista Iberoamericana, Vol. LXXIII, Núm. 220, Julio-Septiembre 2007, 415-436

\title{
PRÁCTICAS INDÍGENAS DE LA RESISTENCIA: SUJETOS DE LA ESCRITURA Y EL SABER EN LOS ANDES COLONIALES
}

\author{
POR \\ Rocío Quispe-Agnoli \\ Michigan State University
}

En el cada vez más amplio contexto académico interdisciplinario que ha estudiado y estudia documentos coloniales producidos por indígenas en Hispanoamérica, el impacto de la escritura alfabética como sistema de comunicación y de significación ideológica ocupa un lugar fundamental. La imposición del sistema gráfico de comunicación que trajeron los europeos provocó reacciones amerindias que van desde la asimilación y apropiación del mismo hasta la resistencia y subversión con el objetivo de representar carencias y necesidades de las sociedades emergentes en el siglo xvi. Indios ladinos, convenientemente instruidos para trabajar como intérpretes lingüísticos y traductores culturales al servicio de la Corona, aprendieron rápidamente el manejo de la retórica legal y se convirtieron en secretarios y escribanos. Algunos de ellos trabajaron en defensa de los derechos indígenas y, al mismo tiempo, buscaron colocarse en un lugar seguro en la nueva sociedad colonial. Otros, en su afán de perpetuar la memoria indígena prehispánica, o debido a su fracaso en el terreno legal, se convirtieron en autores. El Inca Garcilaso de la Vega y Fernando de Alva Ixtlixóchitl deben sus autorías a la primera condición. El cronista andino Felipe Guamán Poma de Ayala es probablemente el ejemplo más contundente, hasta ahora conocido, de la segunda motivación de autoría. Guamán Poma de Ayala, sin embargo, no está solo en su empleo de la escritura para denunciar y remediar la violencia colonial. Lo anteceden autores prolíficos y famosos como fray Bartolomé de Las Casas, así como sujetos desconocidos que escriben cartas al monarca español para quejarse y "descargar su real consciencia”. ${ }^{1}$

Con el fin de hacer escuchar su voz, el indio ladino, desterrado de sus propias tierras y comunidad por la corrupción del gobierno oficial, debe construirse una personalidad textual y discursiva que llame y mantenga la atención de su lector. En este trabajo analizo el sujeto "autor” que Guamán Poma construye y propone a lo largo de su obra principal, la Nueva corónica y buen gobierno (1613-1615). La construcción de la persona del

\footnotetext{
${ }^{1}$ La documentación es amplia e inédita en su mayor parte. Encontramos ejemplos de estos individuos en Cristóbal de Montalvo, Diego Ximenes Canal, Francisco Vásquez de Loayza, entre muchos otros. A título de ejemplo, cito a Montalvo: "Tres cartas escreuí a S.M. del emperador que dios tiene en su gloria y en ellas advertí a su $\mathrm{M}$. de algunas cosas como leal vasallo que convenían al remedio y conversión y conservación de estos naturales y descargo de su real consciencia y su M” (Audiencia de Lima, Lima 121).
} 
“autor” incluye la confirmación de su competencia en tanto productor de textos andinos y europeos, y el reconocimiento de dicha competencia por sus receptores. La tensión que se establece entre los sujetos que funcionan como destinador y destinatario de este texto tiene como característica predominante la construcción de un mensaje que se centra fuertemente en la construcción del sujeto "autor" y en la constitución, mediante la exhortación constante, de los sujetos “lectores”. Con el fin de ocuparme de los sujetos de la escritura en esta obra, deslindaré a continuación los elementos necesarios para definir a estos agentes y sus prácticas de aceptación y resistencia frente a códigos lingüísticos y culturales nuevos. Esto nos lleva al planteamiento de hipótesis relativas al sujeto colonial en la producción de textos de esta época y su relación con las modalidades discursivas del poder y del saber-hacer. En este trabajo, me ocupo principalmente de la constitución, confirmación y reconocimiento del saber del autor, para ser escuchado por sus lectores. Estudio las estrategias textuales mediante las cuales el sujeto “Guamán Poma” opera el paso de la "ignorancia” (no saber) al “conocimiento” (saber), y los roles que se adjudica en su camino hacia tal conocimiento. Planteo como primera hipótesis de trabajo que la función de dicha competencia cognoscitiva es fundamental para lograr el "poder” del agente textual en posición históricamente minoritaria. Para ello, es necesario identificar primero a los sujetos de la enunciación en la Nueva corónica y buen gobierno, sus características y funciones en la producción del texto, y las relaciones intersubjetivas que mantienen.

Es obvio observar que Guamán Poma se plantea como el enunciador principal de la Nueva corónica y buen gobierno. Dicho enunciador entra en relación y tensión con sus enunciatarios, sean estos individuales o colectivos. A su vez, la enunciación que rige al quehacer de producción textual y discursiva del cronista, está regida por la presencia implícita de otros agentes que llamo, siguiendo la terminología de Greimas-Courtés, hiperenunciadores. Guamán Poma reconoce y enuncia a sus hiperenunciadores, aquellas instancias que lo impulsan a producir su texto, y los identifica con las fuentes clásicas que emplea -europeas y andinas-, la inspiración divina que le otorga el “don de la gracia” para escribir y la situación colonial que resulta destructiva para los indígenas. Sin embargo, insisto en la discursivización de los sujetos de la enunciación por medio de las marcas que hallamos en el texto propiamente dicho. Tanto el "autor" como el "lector" que identifica el cronista andino como agentes de su obra, pueden entenderse como configuraciones discursivas, es decir, unidades de discurso con una organización semántica y sintáctica propias, que se integran en unidades discursivas más amplias y adquieren significaciones según el contexto. ${ }^{2}$

\footnotetext{
${ }^{2}$ Entre otros muchos estudiosos de esta crónica, M. López Baralt se ha ocupado de la construcción gráfica de "autor" que realiza Guamán Poma en su obra. Este proceso implica una sucesión de máscaras textuales que se imponen para estar a la altura de su receptor real ("La estridencia...”: 7691, “Un ballo...”: 69-93). Segun López Baralt, el escritor se ficcionaliza a sí mismo y a sus lectores, proceso del cual se aprovecha políticamente para crear imágenes para dichos sujetos. Desde este punto de vista, los lectores deben también inventarse: individual, el rey y el Papa, y colectivo, los estamentos de la sociedad colonial. El autorretrato gráfico que López Baralt registra incluye las máscaras de señor y príncipe; niño educándose en la tradición cristiana; autor rodeado de sus
} 
A partir de la perspectiva anterior, planteo como segunda hipótesis de trabajo en relación a los sujetos de la escritura en esta obra, que Guamán Poma de Ayala, en tanto sujeto de la enunciación que produce textos coloniales en una posición de sujeto dicente en desarraigo o fuera de lugar (Mignolo), descentramiento (Castro-Klarén) o de alteridad (Adorno “Textos...”), nos entrega a lo largo de su obra la adquisición y confirmación de los valores modales del poder y saber gracias a los cuales puede enunciar y efectuar su acto comunicativo con éxito. Creemos que todas las máscaras de las que habla López-Baralt, o las posiciones del sujeto como las llama Adorno, están en función del desarrollo de estas modalidades que constituyen al sujeto de manera efectiva para enunciar. Observamos también que por encima del enunciador, se encuentran hiperenunciadores que lo impulsan a escribir, es decir, que le otorgan los valores modales virtuales del deber y querer hacer, primer paso para la constitución de su competencia. Lo interesante de este proceso es que a lo largo del mismo el autor se construye como sujeto en su poder-hacer (libertad e independencia de acción) en contraste con el no poder-hacer (la obediencia y la impotencia), así como en el saber-hacer (conocimiento). Poder y saber-hacer se combinan para conferir "autoridad" al sujeto, es decir: para convertirlo en "autor”, y lograr la efectividad de su mensaje. El término "autor” que Guamán Poma apropia desde el inicio de su obra, se encuentra semantizado con el sentido de "fuente de autoridad" desde por lo menos el siglo XII. ${ }^{3}$ Los exégetas de la Biblia operaron un cambio de focalización al interesarse, a partir del siglo xIII, en el auctor humano más que en el auctor divino. Con ello, su interés en las Escrituras se vuelve también literario. En este contexto, un auctor era alguien a quien leer, creer y respetar. El auctor realizaba el acto de escribir, y se apoyaba en auctoritas, cuya fuente principal era la Biblia. Dios era el agente que caracterizaba esta autoridad, ya que Él era el auctor de toda la creación y el auctor de palabras. Dios transmitía esta autoridad al inspirar a autores humanos a escribir. Cabe recordar que los escritos de los evangelistas y el Libro del Apocalipsis impulsaban la obediencia a la ley, al buen gobierno si lo pusiéramos en términos de Guamán Poma. Por ello Guamán Poma declara con tono confesional al inicio de su obra, aunque esté cumpliendo con un elemento retórico de su época, que una de las fuentes de su escritura es la gracia divina:

Dios Padre, Dios Hijo, Dios Espíritu Santo, un solo Dios uerdadero que crió y rredimió a los hombres y al mundo y a su madre, la uirgen Santa María, y a todos los sanctos y sanctas y ángeles del cielo. Amén.

informantes de manera semejante al inca rodeado por su consejo; y peregrino en "Camina el autor", en la cual funde las figuras de dioses andinos. Todas estas máscaras son evidentes y fácilmente ubicables en el texto de Guamán Poma. Sin embargo, creemos que se deben pensar u organizar alrededor de las configuraciones discursivas "autor" y "lector" que los sujetos construyen en esta obra.

${ }^{3}$ Para una exposición amplia y detallada sobre la historia de los términos auctor y auctoritas en la tradición medieval europea, véase A. J. Minnis. Extraigo de esta investigación las ideas que aquí expongo acerca de la autoría, el autor y la autoridad. 
Me dé su gracia para escriuir y notar buenos egenplos, para que de ello tome todos los christianos, y cienbre y plante, para que echen buena fruta y cimiente para el seruicio de Dios Nuestro Señor. (f. 3)

En el siglo xiII se define más claramente el oficio del autor para diferenciarse de la labor del escriba (scriptor), el comentarista (commentator) y el compilador (compilator). $\mathrm{El}$ autor es aquel que escribe empleando materiales propios y de otros, pero sus ideas constituyen los temas principales y el empleo de otros autores confirma lo que escribe (Minnis 94). El autor es responsable de lo que escribe y Guamán Poma también lo entiende cuando declara la intencionalidad que lo llevó a escribir (f. 8). Estamos, además, ante un "autor" que adquiere o confirma el poder y el saber-hacer empleando los elementos de dos códigos culturales diferentes.

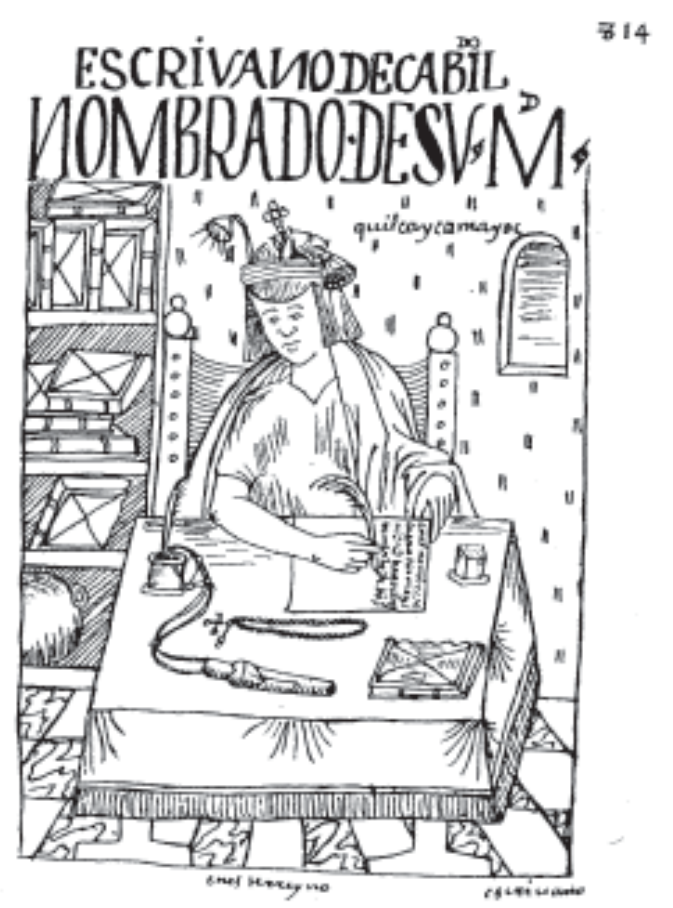

Figura 1: f. 828 (814)

"Escrivano de cabildo"

En este sentido, se trata de un sujeto híbrido que se posiciona entre dos culturas. En la medida en que este sujeto opera la conjunción con ambas modalidades, el poder y el saber, logra un sujeto ideal de la nueva sociedad. Y creemos que este sujeto híbrido ideal se encuentra representado en la imagen y descripción verbal del "escrivano de cabildo nombrado de sv Magestad/ quilcay camayoc" (Figura 1: f. 828), probable alter ego de Guamán Poma de Ayala. Planteo como tercera hipótesis que esta figura, en contraste con otros autorretratos del autor, reúne las modalidades del saber y el poder, desde el punto de vista andino y europeo, que asume el cronista andino a lo largo de su obra. Teniendo en cuenta esta hipótesis de trabajo en relación a los sujetos de la escritura, veamos en más detalle sus recorridos discursivos y textuales para adquirir y ejecutar, mantener, reafirmar o perder el saber.

${ }^{4}$ Cito por folio, y no por página. Sigo la numeración secuencial de folios establecida por Adorno, Murra y Urioste en su edición de la crónica de Guamán Poma. De esta manera, el lector podrá ubicar las citas si sigue cualquier edición de la obra, incluida la facsimilar de 1936. 
El principal enunciador enunciado en la Nueva corónica y buen gobierno se plantea en la figura de "Guamán Poma”. Como ya he dicho, las funciones más frecuentes que él se adjudica tienen que ver con las modalidades discursivas del saber y el poder, ya que se presenta como "autor” y “príncipe”. ${ }^{5}$ A su vez, para constituir su competencia en el saber y el poder, el enunciador, que se manifiesta como "Guamán Poma” tiene ya las modalidades virtuales del deber y del querer-hacer. ${ }^{6}$ El querer y deber-hacer lo plantean como sujeto posible de la enunciación y se actualiza precisamente con los valores del poder y el saber. Voluntad (querer-hacer) y prescripción (deber-hacer) impulsan al sujeto a la búsqueda de la libertad (poder-hacer) y el conocimiento (saber-hacer). En el caso de Guamán Poma, el sujeto cognoscitivo se organiza en una jerarquía de imágenes a lo largo de la obra, las cuales nos remitirán al quehacer del hiperenunciador, las fuentes por ejemplo, que también aparecen enunciadas en el texto. ${ }^{7}$

Las marcas de los sujetos de la enunciación se encuentran a lo largo de toda la Nueva corónica y buen gobierno. Observamos, sin embargo, que hay ciertas partes de la crónica en las cuales las marcas enunciativas son más frecuentes. Los veintiún primeros folios de la obra, por ejemplo, sirven como introducción y en sus páginas encontramos una gran densidad de marcas textuales. Además la extensión de la introducción (21 folios) es muy indicativa de la importancia que el autor adjudica a sus intenciones, y la exposición de ellas, en el momento de redactar la crónica. Estos folios contienen la presentación del libro y del autor; la presentación de la obra al poder divino, papal y real español; una carta de presentación del padre del autor que es evidentemente ficticia; un prólogo al lector cristiano después del cual parece que empezara la narración propiamente dicha con la creación del mundo (f. 12-13), para continuar, sin embargo, en el folio 14 con la historia de la producción del texto hasta el folio 21. El índice de materias que el mismo Guamán Poma incluye al finalizar la obra comienza en el folio 22 con la creación del mundo y del hombre como en el génesis bíblico, por lo cual excluye todos estos textos de la historia propiamente dicha. Vemos ahora de qué manera los sujetos de la enunciación se manifiestan en los folios mencionados.

El enunciador de esta crónica presenta al sujeto "Don Phelipe Guamán Poma de Aiala, señor y príncipe” (Figura 2: portada, f. 1) y lo relaciona explícitamente con la composición de su libro, es decir en tanto "autor”. Después de esta presentación inicial, Guamán Poma habla de las características intencionales de su obra y la inscribe en la

\footnotetext{
${ }^{5}$ Empleamos la aproximación semiótica de las modalidades, la cual se apoya en un número bastante elevado de análisis concretos. Dichos estudios han demostrado el rol importante que desempeñan los verbos modales querer, deber, saber y poder, capaces de modalizar tanto el ser como el hacer de los enunciados (Greimas y Courtés 263).

${ }^{6}$ Proyectado en el cuadro semiótico, las posibilidades lógicas del deber-hacer son la prescripción (deber-hacer), la autorización (no deber-hacer), la prohibición (deber-no hacer) y la permisión (no deber-no hacer). En contraste, la voluntad está regida por el querer-hacer.

${ }^{7}$ A su vez, teniendo en cuenta la actividad cognoscitiva del enunciador y la del enunciatario, hay tres tipos de discursos cognoscitivos: los discursos interpretativos como la historia o la crítica literaria, los discursos persuasivos como la política o la pedagogía y los discursos científicos que se aplican sobre los dos anteriores (Greimas y Courtés 61).
} 
tradición literaria religiosa (el sermón, los confesionarios y la profecía) por su fuerza persuasiva. Es decir, sin nombrar explícitamente a sus destinatarios, los sobreentiende en la apelación que caracteriza a estos discursos. En seguida, el cronista invoca a un hiperenunciador, es decir un sujeto que rige su enunciación: Dios (f. 3). En otros lugares de su crónica reafirma la intervención divina como agente de su escritura: "todo lo fue escriuiendo y sabiendo con abilidad y gracia que le dio Dios y entendimiento para serbir a Dios y a su Magestad” (f. 369). Será este el agente de su enunciación, y su intervención asegura el reconocimiento del saber escribir del sujeto. El primer destinatario

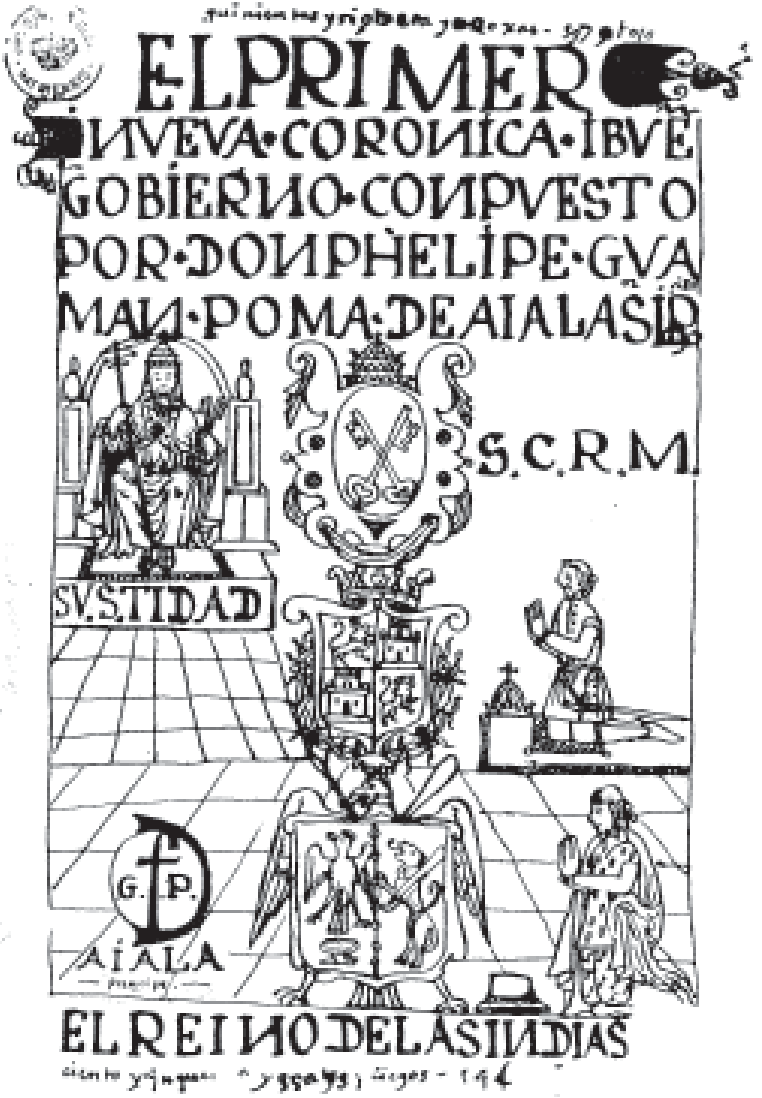

Figura 2: f. 1 Portada individualizado en el texto es el "Mvi santo Padre Papa”, a quien reconoce como “poder de Dios en el mundo”, incluso sobre otros poderes como emperadores y monarcas, y de quien pide un reconocimiento para la recepción y aceptación de su obra, es decir para la puesta efectiva del proceso comunicativo (f. 4).

Hasta aquí se ha presentado la modalidad del saber en el autor y la apelación al reconocimiento del poder del otro, la autoridad que está fuera de él. Sin embargo, inmediatamente a continuación, el cronista inserta una carta formal de su padre, "don Martín Guamán Mallque de Ayala”, quien anuncia al hijo y su obra. Es el padre el que presenta el linaje de la familia del autor y quien, desde su posición de autoridad andina, le otorga poder al hijo al reconocerlo como señor poderoso o cápac: 


\begin{abstract}
Carta de don Martín Guaman Mallque de Ayala, hijo y nieto de los grandes señores y rreys que fueron antiguamente y capitán general y señor del rreyno y capac apo, ques préncipe, y señor de la prouincia de los Lucanas, Andamarca y Circamarca y Soras y de la ciudad de Guamanga y de su juridición de Sancta Catalina de Chupas, príncipe de los Chinchay Suyos y segunda persona del Ynga deste rreyno del Pirú, a la rreal Magestad del rey don Felipe nuestro señor el ssegundo. Dize ací: (...) me a parecido hazer estima del engenio y curiucidad por la gran auilidad del dicho mi hijo lexítimo, don Felipe Guaman Poma de Ayala, capac, ques préncipe, y gouernador mayor de los yndios y demás caciques y prencipales y señor de ellos y administrador de todas las comonidades y sapci y tiniente general del corregidor de la dicha buestra prouincia de los Lucanas, rreynos del Pirú,... (f. 5-6)
\end{abstract}

El título de “cápac”, señor poderoso, que él equipara con el de la nobleza occidental o "príncipe”, inaugura el reconocimiento del poder andino. Además, Guamán Poma se autodesigna “don”, lo cual era considerado en su época como el título que servía de marca distintiva a la nobleza (Lockhart 39). Para la generación de los conquistadores del Perú, el título “don” era prerrogativa de los descendientes directos de la alta nobleza española y de aquellos que ejercían ciertos cargos gubernamentales y eclesiásticos. ${ }^{8}$ Joan de Santa Cruz Pachacuti Yamqui, cronista indígena coetáneo de nuestro autor, también busca realzar su supuesto origen noble en el mundo europeo y americano dándose el título de “don” sumado al tratamiento de "yamqui”, apelativo de los señores étnicos de la zona. Además del título de "don" con el que el padre del autor se designa a sí mismo y a su hijo, se reconocen los cargos de "gouernador mayor de los yndios", "administrador del sapci" y "teniente general del corregidor". También encontramos el empleo de "don" que antecede al nombre de Felipe Guamán Poma, y el de sus parientes y antepasados, en el Expediente Prado Tello [1590-1600], así como los cargos administrativos mencionados: "Don Phelipe Guaman Poma Cacique Principal y Gobernador de los indios y Administrador de las comunidades de la provincia de los Lucanas y Soras, Andamarca y Circa Marca” (PT f. 59). De estas declaraciones se desprenden una serie de características que irán conformando y confirmando no solo la identidad personal de nuestro autor sino su competencia para producir el libro. Su competencia cognoscitiva se confirma en la carta que él mismo le dirige al rey, en la que a modo de captatio benevolentiae emplea fórmulas retóricas identificables con la falsa modestia, lo que era un recurso común en las introducciones o prólogos de textos de esta época:

Muchas ueses dudé, Sacra Católica Real Magestad, azeptar esta dicha ynpresa y muchas más después de auerla comensado me quise bolber atrás, jusgando por temeraria mi entención, no habiendo supgeto en mi facultad para acauarla conforme a lo que se deuía a unas historias cin escriptura nenguna, no más de por los quipos y memorias y rrelaciones

${ }^{8}$ El “don” podía ser transmitido también por el lado materno. En la década de 1530, los “dones” no tenían ninguna dificultad para recibir encomiendas si querían quedarse en el país. Fue precisamente el Virrey Antonio Hurtado de Mendoza, Marqués de Cañete, quien atrajo muchos dones a la colonia peruana y quien los organizó. Para mayor detalle sobre el empleo de este título véase Lockhart 3846. 
de los yndios antigos de muy biejos y biejas sabios testigos de uista, para que dé fe de ellos, y que ualga por ello cualquier sentencia jusgada.

Y ací, cologado de uarios descursos, pasé muchos días y años yndeterminando hasta que uencido de mí y tantos años, comienso deste rreyno, acabo de tan antigo deseo, que fue cienpre buscar en la rudeza de mi engenio y ciegos ojos y poco uer y poco sauer, y no ser letrado ni dotor ni lesenciado ni latino, como el primero deste rreyno, con alguna ocación con que poder seruir a vuestra Magestad, me determiné de escriuir la historia y desendencia... (f. 8).

Como podemos apreciar aquí, el proceso mediante el cual el sujeto inicia la escritura está caracterizado por la adquisición de los valores modales que constituyen su competencia discursiva. El querer y el deber-hacer que instauran a Guamán Poma como sujeto de la enunciación aparecen bajo la forma de una “temeraria entención”, la necesidad de “dar fé de ellos (de sus fuentes nativas)”, su “antigo deseo” de servir al rey. El saber-hacer parece tambalearse por las dudas que lo asaltan en la toma de decisión. Estas dudas se relacionan con dos puntos. El primero es la validez que el enunciatario adjudica a su hiperenunciador andino, quien no maneja la autoridad gráfica sino oral o de otra índole como táctil o visual en el caso de los quipus. Guamán Poma emplea "historias sin escritura”, “quipos”, "biejos y biejas” que sin embargo reconoce como "sabios” y que además son "testigos de vista”, es decir, fuentes viables de la verdad de los hechos que se contarán. El segundo punto que pone en peligro el saber de su competencia enunciativa tiene que ver con el conocimiento que el cronista maneja. Es aquí donde se despliegan las fórmulas retóricas de empequeñecimiento o falsa modestia para ganar la aceptación del receptor. El autor se refiere a su carencia de saber en términos de “rudeza de ingenio” y “ciegos ojos” y a la falta de títulos oficiales del conocimiento: no es letrado, ni doctor, ni licenciado, ni latino. Poco ve, tampoco es testigo de vista como sus fuentes, y poco sabe. No obstante, el deseo de servir al rey, su obediencia como buen súbdito colonial, lo determina a escribir aun con estas circunstancias en su contra. Veremos, sin embargo, que la construcción de su persona que realiza el autor a lo largo de su obra, opera el paso de la ignorancia (no saber) al conocimiento (saber). En cambio, en relación al poder el sujeto se plantea desde el inicio como alguien que ya lo tiene por derecho y lo confirma con sus títulos nobiliarios y administrativos. Sin embargo, con el valor modal del poder sucede lo contrario que con el saber: al final de su relato lo pierde, pasa del poder-hacer (libertad e independencia) al no poder-hacer (impotencia). Sólo le queda el conocimiento acumulado y sus deseos de servir al rey, a la sociedad colonial y a los indios pobres. Con estas observaciones, podemos plantear entonces como hipótesis más específica de trabajo que, desde el punto de vista del saber, Guamán Poma pasa de informante e intérprete a escribano, de allí a notario y luego a autor cronista, rol que conserva a pesar de la pérdida del poder que lo lleva a convertirse en un indio pobre y ermitaño pero sabio. Desde la perspectiva del poder, el sujeto se plantea como poderoso desde el principio, ya que la atribución del poder andino le viene por su linaje familiar y se confirma con los cargos administrativos que él se atribuye en la sociedad colonial. La capacidad de organización que se adjudica el sujeto, presupone tanto el saber como el poder para ejecutar. 
Para comprender mejor la manera en que el sujeto realiza los pasos entre los valores modales del saber y el poder, debemos rastrear los roles específicos que el autor plantea desde el punto de vista de ambas modalidades así como los agentes que hacen posible este paso. Desde la perspectiva del saber-hacer, podemos encontrar al sujeto en el texto como informante, intérprete, escribano, notario, en cargos administrativos coloniales que destacan su capacidad organizacional, quipucamayoc, quilcaycamayoc, traductor, indio ladino, consejero real, ermitaño que anda por el mundo, haciéndose pobre como Jesucristo, testigo de vista y de oídas, educador, crítico de la escritura de otros. Su hiperenunciador aquí son las fuentes andinas, los viejos que le cuentan oralmente y los quipus. Su saber es también europeo y se demuestra en los comentarios que hace a otros autores de su época y en el empleo de tradiciones bíblicas y fuentes religiosas y jurídicas. Él mismo reconoce varias veces la diversidad de los decires que maneja al caracterizarse como "cologado de uarios descursos” (f. 8). Desde el punto de vista del poder, el cronista se presenta como: príncipe, autoridad administrativa, autoridad para confesar y acusar, profeta y predicador investido por el Dios cristiano. Su hiperenunciador se reparte entre su linaje andino que lo entronca con la dinastía inca y con otra nobleza andina no incaica. Hasta aquí he vislumbrado la adquisición y manejo tanto del saber como del poder-hacer en la construcción del sujeto "Guamán Poma de Ayala”. Me concentro a continuación en la descripcion del recorrido que lleva al sujeto Guamán Poma a constituirse como "autor", es decir: su camino hacia el saber-hacer, o de la ignorancia al conocimiento. ${ }^{9}$

Ya hemos dicho que desde los folios iniciales de su obra el cronista se declara como autor y príncipe. Para llegar a ocupar o satisfacer estas posiciones, el sujeto recorre un largo camino discursivo en su propia obra. En ese camino, se adjudica una serie de propiedades, regidas por el saber y el poder, que corresponden a diversos roles sociales. Propongo entonces que el punto de partida para la construcción textual del "autor” es el reconocimiento de su labor como informante e intérprete, como lo hace en la sección del Buen gobierno: "Y e tratado a los padres, corregidores, comenderos, becitadores, ciruiendo de lengua y conuersando, preguntando a los españoles pobres y a yndios pobres y a negros pobres” (f. 715). Aquí Guamán Poma relaciona su habilidad de intérprete e informante con la recolección de datos que le servirá para la escritura de su obra.

Es posible que Guamán Poma de Ayala haya actuado como traductor del Tercer Concilio Limense (1582-1583) ya que conocía la obra de varios de los que participaron allí: José de Acosta, Jerónimo de Oré, Cabello de Balboa (Adorno “Las otras...” 140). Adorno confirma que trabajó como informante e intérprete en su juventud ("The Discursive...”) y posteriormente como secretario, por lo cual entró en contacto con la palabra escrita y empezó a comprender su importancia en el nuevo orden de vida. Trabajó como asistente y traductor de Cristóbal de Albornoz, extirpador de idolatrías, y en 1560 asistió a la campaña española para destruir al Taki Onqoy, movimiento mesiánico que aspiraba a restaurar el orden y gobierno incaicos. Alrededor de 1582 Guamán Poma hizo su primer viaje a Lima con el extirpador Albornoz. Supo entonces de los reclamos de los señores aimara ante el rey Felipe II por la destrucción de sus comunidades a causa de las

\footnotetext{
${ }^{9}$ La adquisición y pérdida del poder-hacer, y sus relaciones con el saber, son motivo de otro trabajo, que estoy realizando en la actualidad.
} 
encomiendas. En 1594 actuó como intérprete de Gabriel Solano Figueroa, oficial visitante en Huamanga (Prado Tello 66v). Al mismo tiempo, trabajó como secretario en las composiciones de tierras en Huamanga entre los años de 1594 y 1595. Más aún, en 1595 certificó como notario público en un reclamo legal por tierras para campesinos de Quinua y al mismo tiempo litigó por las tierras de Chupas. De acuerdo con el expediente Prado Tello, en el que se contienen documentos legales que llevan la escritura y firma del cronista, este asumía a veces el rol de litigante o demandante, y otras el de notario o escribano. Finalmente, en 1600, después de muchos reclamos por tierras usurpadas, recibió una sentencia: un castigo de doscientos azotes en la plaza pública y el destierro de Guamanga. Guamán Poma inició entonces una serie de viajes por la zona. Según Adorno, este es el momento en que Guamán Poma operó el paso de colaborador con iniciativas coloniales a activista de causas andinas. Es más, Adorno piensa que el fracaso de sus reclamos en el terreno legal y el castigo al que se le sometió, lo llevaron a la escritura de la Nueva corónica y buen gobierno (“La génesis...” 10). ${ }^{10}$

La información que el sujeto recibe de los estamentos pobres de la sociedad colonial cuando trabajaba como intérprete inaugura también la constitución de su competencia mediante una serie de agentes que le proporcionan la información que necesita. En términos de la enunciación, se trata de los hiperenunciadores del saber. Este saber se reparte entre sus fuentes andinas, sus fuentes europeas y las que él mismo recoge como testigo de vista u oídas. ${ }^{11}$

En cuanto a sus fuentes andinas, el cronista hace alusión a los quipus y la información oral que recoge de "yndios antigos muy biejos y biejas sabios testigos de uista” (f. 8). Son estos agentes los que proporcionan el material para la Nueva corónica que se centra en la descripción del gobierno incaico. No solo se trata de sujetos andinos, sino que son competentes en el saber y además han visto los hechos con sus propios ojos. A propósito de las coyas, Guamán Poma confirma la veracidad de su historia apoyándose en su fuente: "Que ací lo auía hecho y ací lo cuentan los dichos biejos que lo supieron” (f. 131, cfr. ff. 522, 543), o aludiendo a ella de manera impersonal con la frase: "Dizen que”. El testimonio de vista o de oídas era considerado una fuente fidedigna de infomación en la época en que nuestro autor escribe, y Guamán Poma los emplea (Adorno "Waman..." xxiii). Pero además nos revela una forma alternativa al trabajo erudito de los letrados europeos. Bernal Díaz del Castillo, por ejemplo, privilegia la necesidad de emplear testigos de vista como fuente de evidencia fidedigna y evitar la refutación erudita, ya que el testimonio directo cobra un mayor peso que los préstamos textuales (Adorno “The Discursive...” 212). El

${ }^{10}$ De ser así, Guamán Poma no habría escrito su libro sino hasta después del año 1600. Otros estudiosos, incluida Adorno en trabajos anteriores al descubrimiento del expediente Prado Tello, calculan que el cronista habría comenzado a escribir alrededor de 1585. En todo caso, la excelencia de los materiales de escritura de los que el autor pudo disponer no coincidirían con el estado de pobreza del que se queja en su capítulo añadido, "Camina el autor". Creo que la redacción de este capítulo que añade casi al final de su obra corresponde al destierro con que lo castigaron en 1600, y que lo añadió a la crónica que ya tenía escrita.

${ }^{11}$ En este último sentido, el tratamiento detallado que hace Guamán Poma del régimen virreinal de Toledo parece sacado de su propia memoria (Adorno "Las otras...” 139). 
testimonio en el siglo xvi apoyaba la veracidad de las evidencias en autores sin una larga trayectoria intelectual y, en el contexto del Nuevo Mundo, resultaba pertinente a la escritura historiográfica y jurídica. Aun con la colaboración y su propio quehacer como testigo de vista, el autor se lamenta siempre de que no haya escritura de todo este saber oral que se le transmite. Esto lo lleva a una labor de rescate de la información, y asume la tarea de traducir lo oral en lo escrito (Adorno, Writing 7). La oralidad de las fuentes andinas queda plasmada en la redacción de la Nueva corónica y buen gobierno. El registro oral de

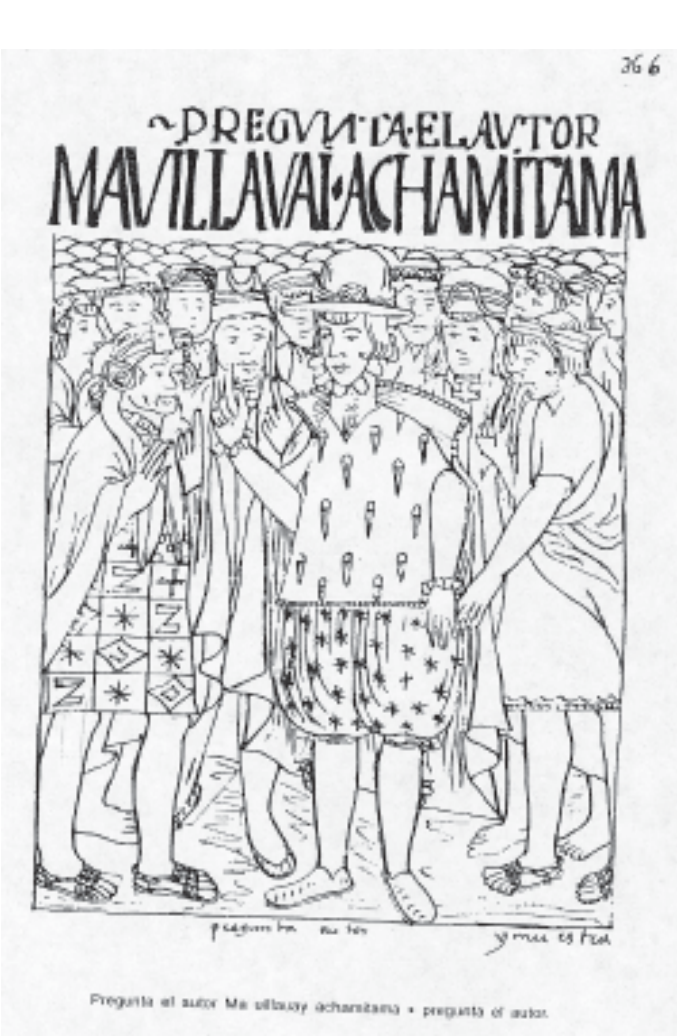

Figura 3: f. 368 (366)

"Pregunta el autor / Ma Villavai" muchos pasajes, así como la imitación del discurso oral de diferentes personajes coloniales que hace el autor, marca la función de testimonio que este sujeto cumple. Es así como el cronista cede su voz a los indios pobres (f. 516), parodia sermones de los padres doctrinantes (ff. 624-626) o imita paródicamente a personajes coloniales (f. 726). Ortega observa en la implementación de esta oralidad en el texto escrito una función metalingüística: Guamán Poma se presenta como un intérprete dedicado al nuevo oficio de la traducción. Y la traducción tiene en su obra una operatividad plural. El sujeto tiene que ser varios sujetos para cumplir satisfactoriamente la enunciación con un destinatario colectivo y diverso (96). De esta manera, el sujeto ejecuta las funciones intermediarias de traductor e invierte su cargo de ayudante de la extirpación: en uno de sus autorretratos (Figura 3 , f. 368), el autor se presenta rodeado por un grupo de

indígenas que le proporcionan información. Se trata de sus hiperenunciadores que lo rodean ofreciéndole la fuente andina. Uno de sus informantes es un indio viejo y noble, que lleva orejeras, signo de nobleza incaica, y cuyo traje se distingue por el tejido de tocapu, una serie de muestras textiles que podría interpretarse como una expresión gráfica 
de información. ${ }^{12}$ Para hacer el dibujo comprensible al destinatario español, Guamán Poma describe en el texto verbal que sigue, la manera en que obtiene la información :

Qve le deglara al avtor/ y muestra los quipos y le declara y le da rrelaciones los Yngas y los Chinchay Suyos, Ande Suyos, Colla Suyos, Conde Suyos al dicho autor don Felipe Guamán Poma de Ayala, administrador, protetor, tiniente general de corregidor de la prouincia de los Lucanas, señor y príncipe deste rreyno, que le declara desde primer yndio que trajo Dios a este rreyno del mutiplico de Adán y Eua y de Noé del [di]luuio primer yndio Uari Uira Cocha y Uari Runa, Purun Runa, Auca Runa, Yncha Pacha Runa; de todo le dio cuenta y rrazón para que lo escriua y aciente en este dicho libro para que la pulicía uaya adelante (f. 369).

Observemos en esta declaración que el sujeto que Guamán Poma plantea como su hiperenunciador andino engloba a todas las etnías andinas del Tawantinsuyu. El saber que adquiere mediante esta fuente se combina con los cargos administrativos coloniales que el autor se adjudica en el plano del poder. Además, el cronista aprovecha la declaración de su fuente para insistir en la cristiandad de los indios antiguos, características indispensable para lograr credibilidad ante el destinatario europeo. La actitud de Guamán Poma hacia las fuentes andinas contrasta con la opinión de los cronistas europeos y el empleo que estos hacen de fuentes similares. La diferencia radica en la relación de identidad/alteridad con la que diferentes cronistas se acercan a estos sujetos. Guamán Poma se ubica como sujeto tanto dentro del mundo andino como del mundo colonial de dominación europea y, por ello, no ve a los andinos como el otro. En cambio, los sujetos colonizadores que producen la mayoría de los textos coloniales en los que incluyen percepciones de los "naturales de las Indias” tienen una visión europeizante desde la cual lo conciben en su alteridad. Es decir, este sujeto colonial que es productor de discursos nativos, y por lo tanto prohibidos en el nuevo régimen, se asocia con prácticas paganas y supersticiosas que contradicen los principios del cristianismo. En consecuencia, sujetos como los indios antiguos que sirven de fuente entran a forma parte, junto con moros y judíos por ejemplo, de los grupos humanos que constituyen la alteridad para un autor español del siglo XVI (Adorno, "El sujeto...” 62). Por esta razón, la visión que aporta Guamán Poma acerca de sus informantes indígenas resulta novedosa y valiosa: para este autor la fuente andina es sabia y cristiana, no pagana. El cronista insiste reiteradas veces en su obra en el carácter cristiano de los indios no sólo en la situación colonial, sino antes de la Conquista. Y explica la caída en la idolatría por los pecados de soberbia y lujuria que atribuye a los monarcas incas, como ya vimos en el capítulo anterior a propósito del registro profético apocalíptico.

Aunque parezca contradecir lo que acabamos de decir, es muy interesante comparar este autorretrato del autor con el retrato del Inca que Guamán Poma presenta justamente dos folios antes. Así, en el folio 366 (Figura 4) se nos entrega la imagen de un Inca rodeado por su “concejo real destos reinos". El personaje que se presenta como Inca se encuentra en el centro del dibujo, vestido con los atributos de la nobleza y un traje pleno de tocapu.

\footnotetext{
${ }^{12}$ Para más información sobre los tokapu como medio gráfico de comunicación, véanse ArellanoHoffmann; y Cummins.
} 


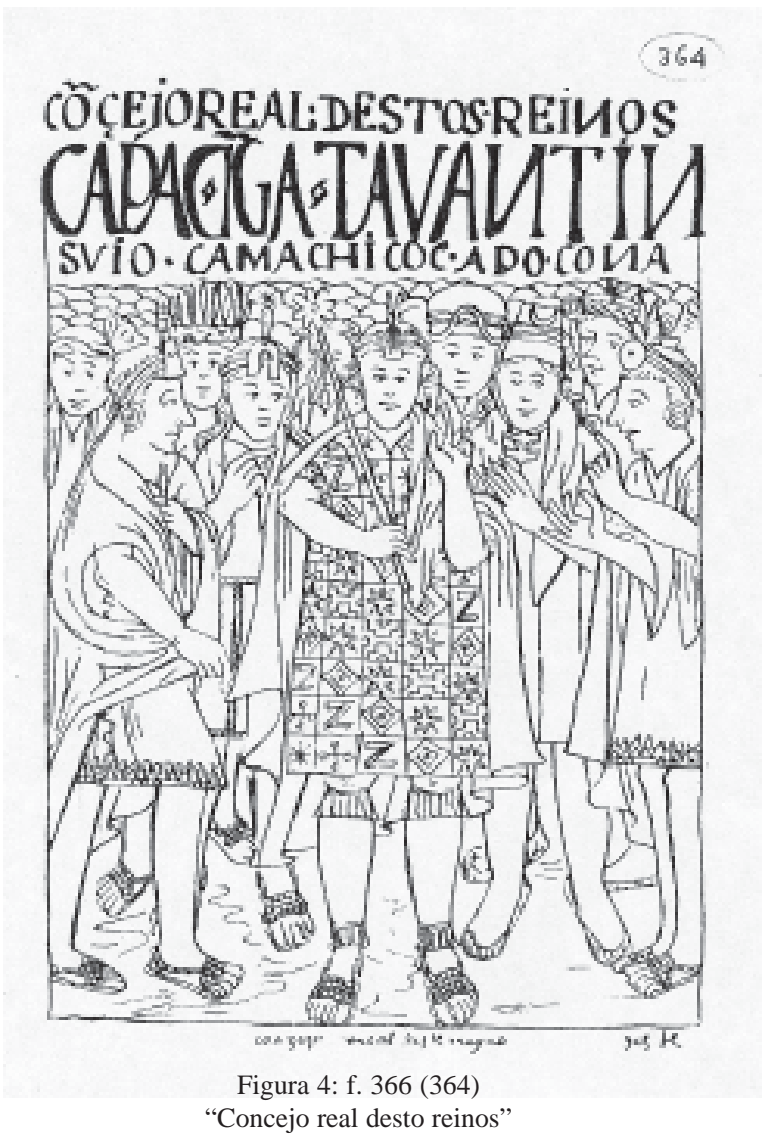

Sus consejeros pertenecen también a la nobleza y se encuentran abocados en la organización del reino, en su buen gobierno (f. 367). El paralelismo que el autor nos entrega aquí no es una casualidad. Su intención es que el receptor de su texto realice la identificación de los personajes centrales (Guamán Poma/ Inca) y su quehacer enunciativo para ordenar la información y organizar sus sociedades. De esta manera, la modalidad del saber que proviene del mundo andino, se enlaza con la situación colonial en la que el cronista desarrolla sus actividades y apoya la capacidad de organización administrativa que Guamán Poma enuncia para símismo. El buen gobierno del régimen incaico se traslada a la propuesta del autor en la nueva sociedad.

Guamán Poma no menciona sus lecturas europeas pero integra las

fuentes orales andinas con obras de la historia europea. ${ }^{13}$ No obstante, el cronista andino admiró mucho a los autores de libros, a quienes califica como "los primeros sauios historiadores de las corónicas pazadas” (ff. 926, 1088-1090). En relación a autores españoles, si bien no los menciona con la frecuencia con que lo hace con las fuentes andinas, hay ciertos escritores que merecen su mención. Uno de ellos es Fray Domingo de Santo Tomás, a quien elogió como erudito (f. 660, 926) aunque critica su obra quechua. Otros autores que merecen su elogio son el "padre maystro Juzepe de Acosta, rretor de la Compañía de Jesús”, “Juan Ochoua de la Sal, prior perpetua de San Juan de Letrán”, “fray Pedro y Gerónimo d’Uré, padre de la horden de San Francisco”. En cambio se refiere a “el

\footnotetext{
${ }^{13}$ Adorno ha estudiado en detalle las lecturas castellanas de Guamán Poma (“Las otras...”), por ello sólo menciono aquí el tema para pasar al siguiente punto de mi argumentación: las fuentes andinas del saber.
} 
padre Cauellos”, “Juan Buemo o Bantiotonio” y “fray Martín de Morúa de la horden de Nuestra Señora de las Merzedes de Redención de Cautibos” con indiferencia o crítica. Lo que el sujeto reclama a los autores criticados es el trabajo de las fuentes andinas que él sí lleva a cabo, sobre todo la ausencia de testigos de vista andinos que Guamán Poma se preocupa en enumerar:

Sacó muy moradas de falta de auiriguación en algunas cosas que escriuen de que ay testigos de bista hasta agora que como son señores, príncipes y principales que duraron de sus uidas más de tienpo de ducientos años, como el príncipe y señor don Martín de Ayala, padre del autor de este dicho libro, que uido y comió con Topa Ynga Yupanqui, Guayna Capac Ynga, Tupa Cusi Gualpa Guascar Ynga. (f.1088)

Después de esta declaración en la que incluye a su padre como testigo de vista, reafirmando el saber y el poder que recibe también a través de sus antepasados directos, Guamán Poma nos ofrece una larga lista de individuos andinos que le han servido de fuente oral y que gozan del privilegio del saber porque han sido testigos de vista. Esta característica también la presenta su padre -o su abuelo-a quien presenta como sujeto del saber y del poder, tanto andino como cristiano. No estamos solamente ante un testigo de vista como los otros que menciona sino ante un testigo de la historia:

Y murió en tienpo de cristiano, seruiendo muchos años a su Magestad en todas las batallas com sennor y príncipe. Y después seruió a Dios en su santa casa del hospital treynta años. Y acabó su uida muy biejo de edad de ciento cinqüenta años, testigo de uista de la historia. (f. 1088)

A los hiperenunciadores andinos y europeos, se añaden aquellos que son coetáneos al autor, que conviven con él en la sociedad colonial. Estos sujetos pueden ser los indios o negros pobres, cuyas quejas y reclamos encuentran una posibilidad de expresión por medio de la escritura de Guamán Poma, sobre todo en el capítulo añadido "Camina el autor”. También se encuentran como fuente de su enunciación las autoridades coloniales con quienes el autor parece haber tratado directamente. En palabras de Adorno, Guamán Poma se convierte en un personificador de voces (1985: 450).

Una fuente de saber y de poder importantísima en la constitución de la competencia del sujeto que se marca como enunciador en la Nueva corónica y buen gobierno está constituida por su linaje familiar. Ya hemos visto la carta ficticia que el padre de Guamán Poma envía al rey presentando a su hijo y a su obra, así como el reconocimiento que se hace a este sujeto como “testigo de vista y de la historia”. Sin embargo, la presencia de la familia de Guamán Poma es recurrente a lo largo de toda la crónica desde el folio 15, en el que aparece necesariamente relacionada al comienzo de su escritura, constituyéndose en uno de sus agentes:

La historia adonde se comensó a escriuirse este dicho libro, Primer corónica y de buen uiuir de los cristianos, que es la historia y uida y cristiandad que pasaron seruiendo a Dios los dichos don Martín de Ayala, segunda persón del Topa Ynga Yupanque, y su mujer, doña Juana Curi Ocllo, coya, hija de Topa Ynga Yupanque, y de sus hijos (f. 15) 
El dibujo que precede a este folio presenta a los padres de Guamán Poma como buenos cristianos. Vestidos como indígenas nobles, ambos llevan rosarios en las manos y parecen bendecir al hermano del autor, el ermitaño Martín de Ayala. Además, este personaje aparece arrodillado y en actitud de recogimiento y lleva también un rosario. La imagen del espíritu santo lo invade para convertirlo en agente de la escritura de la obra, tal como lo declara el cronista en el título de este folio: "Cómo Dios ordenó/ la dicha historia” (f. 14). De tal modo que podemos decir que si bien Dios es uno de los hiperenunciadores que hace posible la acción del enunciador, realiza su acción no sólo directamente sino también por medio del hermano santo del autor. De esta manera, Guamán Poma traslada la cristiandad y santidad al lado nativo y familiar, en primer lugar en la figura de Martín de Ayala, hermano santo, cuyo retrato es el reverso del cura español. ${ }^{14}$ La vida de este personaje transcurre en medio de sufrimientos y penitencias que se autoimpone, configurándose como la figura central de un discurso hagiográfico: "Y rrecibió el áuito de hermitaño de edad de doze años y le puso en estudio y dotrina; con sus propias manos le castigaua, el qual por donde uino a creser” (f. 15); "En el dormir dormía poco y tenía por frezada y collchón estera tejida de paxa y tenía un gallo por rreloxo en la cauesera, para que le despertase a la oración y para uecitar de los pobres enfermos. Y rresaua sus maytines y nona, uísperas y se daua muy muchas deseplinas en su carne. Toda su uida trayya selicio, jamás trayya camisa en el cuerpo” (ff. 18 y 19). La vida de santo ejemplar que lleva el hermano de Guamán Poma está impregnada de virtudes como la humildad, la castidad, la obediencia y la gracia de Dios. Finalmente muere como mártir al servicio de Dios durante el período de la conquista:

Y ancí se bolbió, como dicho es, otra ues al dicho hospital de la ciudad del Cuzco como hirmitaño. Y trajo por muy gran rregalo una enfermedad que le dio Dios, enfermedad de los Andes. Y de ello dio gracias a Dios, como dicho es, este sancto hombre padre Martín de Ayala, hermitaño. Y después fue padre saserdote, clérigo de misa. Y murió en el dicho hospital de la ciudad de Guamanga (f. 463).

La historia de la vida ejemplar de Martín de Ayala se vuelve a repetir completa y con los mismos detalles en el capítulo en que exhorta a los padres (ff. 612-613), a quienes se los presenta como modelo de vida ejemplar. Más adelante lo incluye de nuevo como agente de sentencias para propiciar las actitudes del buen cristiano (f. 747). Además de confirmar su competencia cristiana, este sujeto también le otorga saber al enunciador ya que es él quien, inspirado por el Espíritu Santo, le enseña a leer y escribir al autor y le indica el camino de la cristiandad con una biografía ejemplar: "Y el dicho sancto hombre le enseñó a sus hermanos y al autor deste dicho libro, por dónde se bino a escriuirse la dicha Primer corónica por este dicho galardón mestizo, por los uertudes y oraciones que hazía este dicho cacique prencipal y su señora” (ff. 15 y 17 ).

A la santidad del hermano del autor, se añade la de su padre “don Martín Guaman Mallque de Ayala”. Este salva la vida del capitán general Luis Dávalos de Ayala “muy gran

${ }^{14} \mathrm{Al}$ respecto, véase también Cánovas 65. 
seruidor de su Magestad”, quien además es padre del hermano mestizo Martín de Ayala. El capitán le agradece dándole su nombre, el cual pasa al autor recordando la hazaña cristiana del padre (ff. 16 y 394). El rasgo de cristiandad es tan importante para la identidad del autor y de su familia como para toda la colectividad indígena: de allí los esfuerzos de Guamán Poma por demostrar la tradición cristiana de los indios antiguos anteriores a la dinastía. Creo que aquí radica un rasgo importante en relación con la escritura y el sujeto que propone Guamán Poma. Si bien este autor insiste obsesivamente en el carácter cristiano de él y de su familia para lograr la aceptación de su enunciación, también extiende este argumento a toda su raza y trata siempre de demostrar el cristianismo de los indios antiguos con un fin político: demostrar que no era necesaria la guerra de la conquista o más aún, que hubo conquista pacífica sin guerra, por la buena y cristiana disposición de los indios. En la demostración de tal tesis, el autor andino coloca a su padre como pieza fundamental de las relaciones diplomáticas entre europeos y andinos (ff. 423, 433, 435, 564).

Además de destacar su carácter cristiano, el padre del autor se presenta también con todos los títulos nobiliarios y cargos andinos que permiten reconocerlo como hombre de poder: es segunda persona del Inca y como tal virrey, embajador del emperador Carlos (ff. 16 y 564), recibe a los conquistadores en Tumbes y en Cajamarca, es un poderoso señor y guerrero leal al monarca español en el período de la conquista (ff. 377, 423), príncipe que da sentencias morales de la misma manera en que lo ha hecho el hermano ermitaño del autor (f.750). La historia del padre del autor, caracterizado como agente conquistador y poblador de las tierras de Guamanga, se presenta en el expediente Prado Tello, con la exaltación de su cristiandad. Sin embargo, los títulos que el cronista otorga a su padre en este texto se encuentran bastante lejos de la construcción que presentará en su crónica:

Don Martin de Ayala Señor y Gobernador fue primer conquistador y poblador de la ciudad de Guamanga y fue hijos y nietos de los mayores señores de estos reinos y Señor del valle de Chupas y de los primeros que recibió a los cristianos en Caxamarca y el primero que recibió la nuestra Santa Fe Católica y primero que se bautizó y se caso y recibió el cuerpo el Señor a cincuenta años y primer hermano en la Cofradía y hermano de la Limpia Concepción y sirvió a su Majestad en las guerras cuando se rebeló contra la Corona Real de Su Majestad Geronimo Pisarro con Don Diego Senteno (...) Ha servido en todas estas guerras que están declaradas a Su Majestad y sirvió y fue por Capitán General a la entrada de Vilcabamba, conquista de los Yngas, por mandado del Señor Don Francisco de Toledo Virrey de estos reinos, y después sirvió a Dios Nuestro Señor en su Santa Casa más de treinta años sin interés en el hospital de los naturales, y murió en su santo servicio de ochenta años y se enterró en la Iglesia de San Francisco a donde fue hermano, y dejó por Señor y heredero legítimo a su hijo legítimo Don Phelipe Guaman Poma (Prado Tello 49v).

Como se puede observar en esta cita, los atributos del padre están más bien dirigidos a la demostración de propiedad de tierras en el valle de Chupas, que se encontraban en litigio. Además, en esta descripción del padre se mezclan atributos del abuelo, los cuales se deslindan claramente en la Nueva corónica y buen gobierno. Sin embargo, el folio que precede a éste contiene un dibujo del abuelo del autor "Guamán Malque de Aiala cacique 


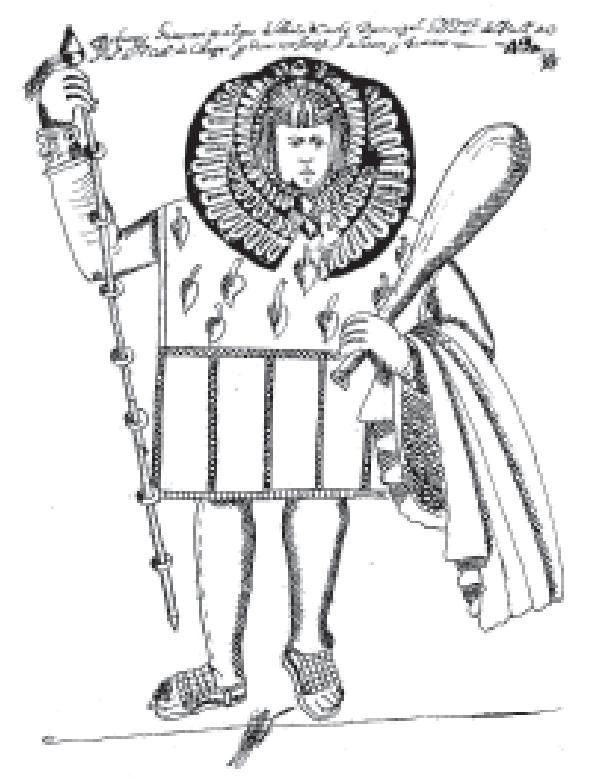

Figura 5

Guamán Chava, abuelo del autor Expediente Prado Tello principal” (Figura 5) tal como lo representa en la crónica en tanto “El doze capitán, Capac Apo Guaman Chaua” (Figura 6, f.167). ${ }^{15}$ Por último, la insistencia en su carácter cristiano es semejante a la que se escribe en la crónica. Finalmente es en este documento donde Guamán Poma repite una vez más la historia noble y guerrera de su padre cuando ya se encuentra como hombre pobre desterrado (f. 916917) y se lamenta de la pérdida de poder que ha sufrido su familia.

Al lado de la figura del padre que otorga competencia en el poder al autor y confirma su identidad cristiana, se encuentra la del abuelo Guamán Chaua. Este sujeto se presenta en el texto con las misma atribuciones que el padre del autor y aparece enunciado por primera vez en el recuento de los antepasados del cronista en la cuarta edad de indios, una época en la que había mucha justicia y orden (ff. 7176). Guamán Chaua surge en el texto

como un señor poderoso al servicio del Inca organizador Topa Yupanqui (f. 111), con cuya hija legítima se casa (f. 176). El abuelo del autor tiene un retrato y biografía individuales en el capítulo dedicado a los capitanes andinos, en el cual se destacan sus virtudes guerreras (f. 168). Además, también participa del saber al ocupar el puesto de virrey del inca (ff. 186, 341, 343). La imagen del abuelo guerrero acompaña a las de otros antepasados y parientes del autor, quienes se hacen presentes en el capítulo de la conquista. Ellos defienden y salvan al monarca español de los traidores (f. 435). Más tarde, en la primera parte de la sección de Buen Gobierno, el autor realiza un reconocimiento del valor

\footnotetext{
${ }^{15}$ Los nombres de los que serían abuelo y padre de Guamán Poma de Ayala se superponen confusamente en el expediente Prado Tello. Según las observaciones de Pablo Macera al examinar el expediente, surgen los siguientes problemas: "El imponente retrato de la foja 49 presentaría a Domingo Guamán Mallqui de Ayala, quien en diversas fojas posteriores es mencionado como padre de Felipe Guamán Poma de Ayala; sin perjuicio que otros párrafos atribuyan esa filiación a Martín de Ayala. [...] No son muchas las veces que en el Expediente aparece Domingo Guamán Mallqui. La primera mención como dijimos corresponde a la foja 49 que con toda claridad lo califica de Cacique Principal Gobernador del Valle del Pueblo de Santa Catalina de Chupas y de sus mojones alisos y tierras. Sin embargo, la foja 49v, no habla de Domingo sino de Martín de Ayala”. Para una detallada exposición de las hipótesis acerca de estas confusiones textuales véase Macera 36-39.
} 
y los servicios que tanto él como sus antepasados prestan al rey español. Observamos aquí cómo el autor andino traslada los valores de la cultura masculina, cristiana y caballeresca militar sobre la representación de sus antepasados en su obra. ${ }^{16}$ De esta manera, se podría identificar a Guamán Poma como un sujeto con una visión colonizadora que poetiza sobre los líderes indígenas. Adorno apunta al respecto que el cronista destaca el heroísmo individual de los señores nativos, cuyos actos autóctonos sirven de modelos de conducta caballeresca ("El sujeto..." 65). Sin embargo son los invasores españoles los que dependen de la táctica política y guerrera de los príncipes autóctonos. Mientras que estos se presentan como valerosos guerreros, los soldados europeos flaquean cobardemente. En este sentido, Guamán Poma comparte con otros cronistas indígenas, como el mexicano Alva Ixtlixochitl, la insistencia en la lealtad que sus antepasados demuestran al monarca español (ff. 433-436), a quienes destacan como héroes que siguen modelos de conducta caballeresca (65 y 1995b: 35). [La paginación puede provenir de cualquiera de los dos consignados en la bibliografía]. Además, partiendo de su reflexión sobre el sujeto colonial y la construcción de la alteridad en los siglos XVI y xVII, confirma la impresión de que ambos cronistas producen sujetos de

${ }^{16}$ Adorno se ocupa de esta visión del indígena americano cuando analiza la construcción de la alteridad en el discurso colonial hispanoamericano desde el punto de vista del sujeto colonial, tanto el colonizador como el colonizado. Nos interesa la configuración discursiva "natural de las Indias" en las tres vertientes que analiza: (1) en tanto sujeto colonizado y protagonista de acciones militares épico-caballerescas, (2) en tanto lector de discursos europeos y productor de discursos nativos, según una visión europeizante, y (3) como productor de discursos históricos y focalizador del discurso europeo colonial (“El sujeto...” 57). Desde el punto de vista europeo, el sujeto colonial nativo por su “torpeza fimínea” no podía distinguir la verdad de la mentira del mundo nuevo de las letras. Había que educarlo pero paternalmente. En tanto productor de discursos nativos, se trataba de discursos prohibidos, prácticas paganas y supersticiosas que se combatían, discursos que se eliminaban. En tanto productor de discursos históricos, había que desfiminizar la cultura nativa siguiendo dos estrategias: a) la racionalización (extirpar idolatrías) y b) la restauración de la historia (62-64). 
escritura que se encuentran en un discurso caballeresco, ya que mantienen una posición fundamental de élite o aristocrática y se plantean como representantes de una tradición guerrero-militar. Volviendo a la construcción genealógica del autor de la Nueva corónica y buen gobierno, son los conquistadores, a los que el abuelo de Guamán Poma recibió amistosamente en tanto embajador del Inca, los que matan por codicia y con suma crueldad a Guamán Chaua, convirtiéndolo en una de las primeras víctimas del desorden de la conquista, y cuya muerte semeja a la de los mártires cristianos:

Don Francisco y Don Diego de Almagro y los demás cristianos le mandaron tapear al excelentísimo señor, capac apo Guaman Chaua, segunda persona del Ynga, que estaua bibo muy biejo y los demás señores grandes. Le enserraron, pidiéndole oro y plata como enteresado y cudicioso en oro y plata. Estos dichos conquistadores le echó fuego y le quemó, acabo su uida. (f. 399)

Más adelante, sin embargo, el autor presenta otro retrato de su abuelo, vestido como personaje colonial español aunque sus títulos sigan siendo de cacique principal y príncipe andino (f. 833; Figura 7, f. 755). El cambio de vestido es simbólico de la necesidad de adaptación al nuevo sistema que se extiende incluso al pasado. Guamán Poma explica que su abuelo es príncipe tanto en el mundo andino como en el mundo español, y que uno de los rasgos que lo diferencian es el vestido:

Como cacique prencipal y príncipe an de deferenciar el áuito. A de bestirse como español pero deferencie que no se quite los cauellos que se la corte al oydo. Trayga camisa, cuello, jubón y calsa, botas y su camegeta y capa, sonbrero y su espada, alauarda y otras armas como señor y prencipal y caballos y mulas. Y se ciente en una cilla, tiana, y que no tenga barbas porque no paresca mestizo. (f. 756)

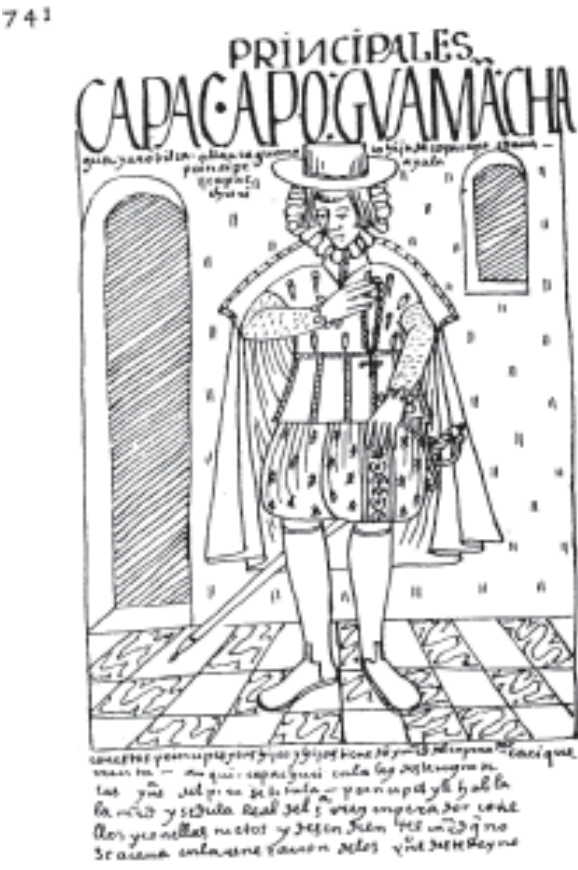

Figura 7: f. 755 (741)

“Principales/ Capac Apo Guaman Chagua”

El planteamiento de su abuelo como personaje colonial le permite legitimar su nobleza. De acuerdo con su razonamiento los andinos que han tenido poder antes de la conquista lo mantienen en el período colonial, 
de allí que Guamán Chaua aparezca como noble durante el reinado de los Incas y luego en el período colonial. Como podemos observar, la imagen del abuelo guerrero y caballeresco que sirve a los Incas primero y luego al rey de España sufre una transformación en el texto para convertirse en un personaje de la nobleza colonial andina, con la cual probablemente el autor se identifica con mayor facilidad.

De esta manera apreciamos que el sujeto enunciador de la Nueva corónica y buen gobierno emplea su tradición familiar con cuatro funciones o intenciones textuales que convienen a la construcción de su competencia: para apuntalar su posición de poder en el mundo andino, para mostrarse portador de conocimientos que pasan de generación en generación hasta llegar a él, para resaltar su carácter cristiano y asegurar que el autor también lo es y para demostrar su lealtad al rey español.

Solo a título de introducción para continuar esta investigación, recordemos que en el análisis del recorrido discursivo de los sujetos para constituirse en el texto, apreciamos también que si bien el enunciador se plantea desde el principio como sujeto poderoso (“príncipe”) y sabio (“autor”) opera al final un cambio que le resulta doloroso y que le permite acusar con más fuerza. En su capítulo añadido de “Camina el autor” (ff. 11051139) Guamán Poma nos entrega el relato de la pérdida del poder, ya que reconoce que ha pasado de "príncipe” a "pobre”. Su única opción es andar por el mundo como un "ermitaño" que se comporta como un "buen cristiano", ofrece consuelo a los "indios pobres de Jesucristo” y dice ser discípulo de un ficticio “Cristóbal de la Cruz”. Es en este momento de la narración en que se hace más evidente la integración del enunciatario en la producción del texto, ya que es él quien interpreta el quehacer enunciativo del sujeto y lo reconoce, o no, como “autor”. Al hacerlo, le da legitimidad no sólo al enunciador sino a su mensaje. López Baralt apunta al respecto una característica de la tensión intersubjetiva en esta obra: la narración en tercera persona se interrumpe constantemente por la segunda para apostrofar al lector, cuya intervención es fundamental en la producción del texto. Se trata además de un yo airado que se dirige a un tú censurable ("La estridencia...” 91). Sin embargo, creemos que en el momento casi final del relato en que el sujeto ha sido despojado del poder, el enunciador se hace uno con el enunciatario, lo engloba haciendo también una la enunciación del texto. Y esto lo manifiesta en una frase que hace evidente su personificación de diversas voces coloniales: "soy todos bosotros” (f. 964). De esta manera, mediante la personificación de diversas voces coloniales, el yo amerindio que se reconoce en la agencia textual de Guamán Poma de Ayala, se fusiona con el otro colonial colectivo, europeo y amerindio. Por lo tanto, el camino hacia la adquisición del saber y la ejecución del poder tiene como resultado la incorporación de alteridad e identidad en un área en la cual los límites entre el yo y el otro se borran, las diferencias entre los sujetos -que se plantean como excluyentes y enfrentados en el pensamiento occidental- se disipan. Esta indiferenciación es lo que J. Lacan identificaría como la vuelta al estadio anterior al del espejo. Se trata de un estadio pre-cultural en que los seres humanos viven en un mundo de indiferenciación: no hay límites claros entre el yo y el otro. El hombre occidental deja este estadio cuando se afirma en su yo y construye su identidad por exclusión de sus otros. Una excesiva identificación con el otro genera en el hombre occidental el miedo a la pérdida de esta diferencia. Sin embargo, el yo que enuncia en la 
Nueva corónica y buen gobierno es un yo y un agente amerindio, que integra al otro como parte de sí. Estamos, por lo tanto, ante una posibilidad de fusión entre identidad y alteridad, que es difícil de imaginar y aceptar para el pensamiento occidental, pero que parece proponer el texto andino. Quizá en este conjunto de textos producidos por agentes amerindios podamos encontrar un ingrediente más de la pregunta por la identidad latinoamericana. Esto nos revela, por último, que lo amerindio sigue siendo una parte inexplorada, desconocida, y muchas veces negada, de la naturaleza del yo latinoamericano contemporáneo.

\section{BibliografÍA}

Adorno, Rolena. Writing and Resistance in Colonial Perú. Austin: University of Texas Press, 1986.

“Las otras fuentes de Guamán Poma: sus lecturas castellanas”. Histórica 2/2 (1978): 137-58.

“Waman Puma: el autor y su obra”. Nueva coronica i buen gobierno. [1613-1615]. Rolena Adorno, John V. Murra y Jorge Urioste, eds. 3 vols. Madrid: Historia 16, 1987. xvii-xlvii.

“El sujeto colonial y la construcción cultural de la alteridad”. Revista de Crítica Literaria Latinoamericana 14/28 (1988): 55-68.

"The Discursive Encounter of Spain and America: The Authority of Eyewitness Testimony in the Writing of History”. The William and Mary Quartely 49 (1992): 210-28.

"La génesis de la Nueva corónica y buen gobierno de Felipe Guamán Poma de Ayala”. Taller de Letras de la Pontificia Universidad Católica de Chile 23 (1995a): 9-45.

"Textos imborrables: posiciones simultáneas y sucesivas del sujeto colonial”. Revista de Crítica Literaria Latinoamericana 21/41 (1995b): 33-49.

Arellano-Hoffmann, Carmen. “Khipu y Tokhapu. Sistemas de comunicación inka”. Los Incas, arte y símbolos. Franklin Pease G. Y. et al., eds. Lima: Banco de Crédito del Perú, 1999. 215-62.

Audiencia de Lima. Cartas y expedientes de personas seculares del distrito de dicha Audiencia. Archivo General de Indias de Sevilla. Legajos Lima 121, 145, 309.

Cánovas, Rodrigo. Guamán Poma, Felipe: escritura y censura en el Nuevo Mundo. Santiago: Francisco Zegers, 1993.

Castro Klarén, Sara. “El orden del discurso en Guamán Poma”. Revista de Crítica Literaria Latinoamericana 21/41 (1995): 45-67

Cummins, Thomas. Toasts with the Inca. Ann Arbor: University of Michigan Press, 2002.

Greimas, A.J. y J. Courtés. Semiótica. Diccionario razonado de la teoría del lenguaje. Madrid: Gredos, 1982.

Guamán Poma de Ayala, Felipe. Nueva coronica i buen gobierno. [1613-1615]. Rolena Adorno, John V. Murra y Jorge Urioste, eds. 3 vols. Madrid: Historia 16, 1987.

Lacan, Jacques. “The Mirror Stage”. Ecrits. A Selection. Alan Sheridan, trad. New York: Norton, 1977. 1-7. 
Lockhart, James. Spanish Peru 1532-1560. A Social History. [1968] Madison: University of Wisconsin Press, 1994.

López Baralt, Mercedes. “La estridencia silente: oralidad, escritura e iconografía”. La Torre 3/2 (1989): 609-49.

"Un ballo in maschera: hacia un Guamán Poma múltiple”. Revista de crítica literaria latinoamericana 21/41 (1995): 69-93.

Macera, Pablo. “Introducción”. Y no ay remedio (Expediente Prado Tello 1560-1640). Lima: Centro de Investigación y Promoción Amazónica, 1991. 25-80.

Mignolo, Walter. "Decires fuera de lugar: sujetos dicentes y formas de inscripción”. Revista de crítica literaria latinoamericana 21/41 (1995): 9-31.

Minnis, A. J. Medieval Theory of Authorship. Philadelphia: University of Pennsylvania Press, 1988.

Ortega, Julio. “El cronista indio Guamán Poma y la conciencia cultural”. El discurso de la abundancia. Caracas: Monte Ávila, 1990. 105-29.

Prado Tello, Mons. Elías. Y no ay remedio (Expediente Prado Tello 1560-1640). Lima: Centro de Investigación y Promoción Amazónica, 1991.

Santa Cruz Pachacuti Yamqui Salcamaygua, Joan de. Relación de antigüedades deste reyno del Perú [1613]. Madrid: BAE, 1968. 281-319. 